\title{
Correlation of the risk of breast cancer and disruption of the circadian rhythm (Review)
}

\author{
GIULIA COSTANZA LEONARDI ${ }^{1 *}$, VENERANDO RAPISARDA $^{2 *}$, \\ ANDREA MARCONI ${ }^{2}$, AURORA SCALISI ${ }^{3}$, FRANCESCA CATALANO ${ }^{4}$, LIDIA PROIETTI $^{2}$, \\ SALVO TRAVALI $^{1}$, MASSIMO LIBRA $^{1}$ and CONCETTINA FENGA ${ }^{5}$ \\ ${ }^{1}$ Laboratory of Translational Oncology and Functional Genomics, Section of Pathology and Oncology, \\ Department of Bio-Medical Sciences, ${ }^{2}$ Section of Occupational Medicine, Department of Internal Medicine \\ and Systemic Diseases, University of Catania, Catania; ${ }^{3}$ Secondary Prevention and Screening Gynecological \\ Unit, AUSL 3, Catania; ${ }^{4}$ Senology Unit, Cannizzaro Hospital, Catania; ${ }^{5}$ Section of Occupational Medicine, \\ Department of Social and Environmental Medicine, University of Messina, Messina, Italy
}

Received February 22, 2012; Accepted March 26, 2012

DOI: $10.3892 /$ or.2012.1839

\begin{abstract}
Breast cancer is the worldwide leading cause of cancer incidence among women. Night shift work exposure has been recently considered one of the significant breast cancer risk factors in industrialized countries. The mechanisms by which this work exposure may be responsible for cancer development is still discussed. In the last 15 years, many authors have paid attention to the relationship between night shift work and breast cancer risk. In the current study, eight case-control studies and four prospective epidemiological studies describing such relationship are discussed. A positive correlation between night shift work and breast cancer risk was described in 8 out of 12 studies. However, different reasons suggest that some of these studies have an Achilles heel according to the International Agency of Cancer (IARC) indications. Both the circadian system alteration and the melatonin output reduction, related to the exposure to light-at-night during night shift work, remain the most valid hypotheses on the causal relation of shift work and breast cancer. Overall, the results of the present study suggest that there is an association between night shift work and breast cancer development in western countries. However, further studies are needed to confirm such association and to understand which biomolecular mechanisms may be involved in the pathogenesis of cancer diagnosed in patients with night shift work exposure.
\end{abstract}

Correspondence to: Dr Massimo Libra, Department of BioMedical Sciences, Pathology and Oncology Section, Laboratory of Translational Oncology and Functional Genomics, University of Catania, Via Androne 83, 95124 Catania, Italy

E-mail: mlibra@unict.it

${ }^{*}$ Contributed equally

Key words: breast cancer, shift-work, cancer risk, night-work

\section{Contents}

1. Introduction

2. Methods

3. Case-control studies analyzing the relationship between breast cancer risk and shift work exposure

4. Cohort studies analyzing the relationship between breast cancer risk and shift work exposure

5. Discussion

\section{Introduction}

Breast cancer has an important impact on the health of women. It is the worldwide leading cause of cancer incidence among women, accounting for over one-fifth of the estimated annual 4.7 million cancer diagnoses in females, and the second most common tumour, after lung cancer in both genders (1-3). It is also the worldwide most common cause of death from cancer among women with about 375,000 deaths in the year 2000 (1-3). Furthermore, there is a considerable variation in the incidence of the disease among different regions with higher rates in most industrialized areas than in least industrialized (4). Fifty percent of all breast cancer cases can be attributed to known risk factors (5), primarily lifetime burden of estrogen (6-8), alcohol (9), adiposity and weight gain (10), but there is no consensus on what are the major causes of the international differences in risk of breast cancer $(5,11)$.

The advent of electricity in our society has extended the lighted period allowing a large numbers of people to work at night. In industrialized countries about $15-20 \%$ of the working population is involved in night working regimens or in intercontinental travel across several time zones (timewindows that contain the so-called biological night) (12). In the past decades different studies and reports refer to shift work as one of the most upsetting factor of the biological homeostasis as it is responsible of a mismatch between the endogenous circadian timing system and the environmental synchronizers (the light-dark cycle in particular) with 
subsequent disturbances of the normal circadian rhythms of physiological functions (13). This phenomenon is connected with short-term effects 'jet lag' syndrome and long-term health effects such as alterations in lipid metabolism (14-17), carbohydrate metabolism and insulin resistance $(16,18)$, grow th hormone (19) and corticosteroid secretion patterns and blood concentration $(20,21)$.

First, it was hypothesized that the rising risk of breast cancer in industrialized areas was partly due to the increased use of electric light during night time (22). The mechanism underlying this hypothesis has evolved from merely a question of suppression of melatonin output to a question of disruption of circadian rhythm and interaction with clock genes (23). In the last 15 years, several studies have focused on the relationship between shift work and breast cancer risk. However, these studies remain controversial. In fact, Megdal et al in a meta-analysis of 13 studies showed that night shift work increases the risk of breast cancer by $48 \%$ (24). In contrast, only a limited evidence for a causal association between night shift work and breast cancer has been described by Kolstad in a critical review published in 2008 (25).

In the present study an update of the literature on the shift work and breast cancer risk, by examining all previous published studies, is carried out. Potential mechanisms by which night shift work exposure may be responsible for cancer development are also discussed.

\section{Methods}

In the present study a computerized search in PubMed was conducted in October 2011. Search terms included 'night work', 'night shift' or 'shift work', 'circadian rhythm' or 'circadian disruption' and 'cancer' and risk terms (breast, breast cancer, risk and breast cancer risk). Night shift work was defined as any shift schedule that included overnight work. All of the abstracts were reviewed and the final set of studies was decided upon. Only original epidemiologic studies, specifically analyzing night or shift work and the risk of breast cancer, were included. Any restrictions with regard to place of origin or race of the women were not placed. Animal studies, reviews, and studies that did not provide separate risk analyses for breast cancer were excluded. Any study that did not separate women from men was also excluded. Epidemiologic studies of pilots, flight attendants, physician, radiologist, military and police employees, fire fighters, or police and law enforcement personnel that have been included in previous review articles were not included since these studies did not specifically include any information about night shift work for the study participant $(26,27)$. According to our inclusion criteria, 12 studies were identified. Of these, 8 were retrospective and 4 prospective (Tables I and II).

\section{Case-control studies analyzing the relationship between breast cancer risk and shift work exposure}

Table I shows 8 case-control studies describing the relationship between breast cancer risk and shift work exposure. A positive correlation between shift work and breast cancer risk was described in 6 out of 8 studies (28-35). Below are reported in detail the results from each study.
Tynes et al (28) conducted a nested case-control register-linked study among 2619 women, radiotelegraph operators, who had worked on merchant ships. The source of outcome information was the Cancer Registry of Norway where 50 cases of breast cancer were identified and 259 age-matched controls were drawn from within the study population. Job histories of the operators were obtained from the seamen register. Shift work (categories $0,1,2$, and 3) and travel through time zones (categories 0 and 1) were classified for each ship mentioned in the job histories by a shipping journalist and a researcher with detailed knowledge of the recent history (1945-90) of Norwegian merchant ships. 'Shift work', in this classification, reflected frequent presence in the radio room both at night and during the day. The longest exposure assessed by the study was $>3.1$ years. The total work history since certification was considered as exposure period. The index obtained by the multiplication of the shift work variable with the number of years employed in each category was used together with the duration of employment to perform the analyses. For participants born in 1935 or later the analyses were adjusted for a fertility variable (no children, years at birth of first child) but the information was incomplete for participants $>50$ years, whereas they were apparently complete for women $<50$ years. Among those aged $>50$ years, an odds ratio of 5.9 (95\% CI) was observed when the group of operators in the highest category (employed for $>3.1$ years) was compared with operators never undertaking night shift work. Further, in women aged $>50$ years a significant exposure-response relationships were found for duration of employment $(\mathrm{P}=0.02)$ and shift work $(\mathrm{P}=0.01)$. For the operators who were not yet 50 years old there was no excess of risk. In conclusion the study showed a possible association between breast cancer and shift work mostly in women above 50 years of age.

In the USA, a study conducted by Davis et al (29), patients were represented by 813 women aged $20-74$ years with a diagnosis of breast cancer (ICD-O site codes 174.0-174.9) between November 1992 and March 1995 and were identified by the SEER (Surveillance, Epidemiology and End Results of the NCI); control subjects were 793 woman, aged 20-74 years with no history of breast cancer selected to be equal in number to the case patients and frequency matched according to 5-year age groups. An in-person interview was used to determine information on known or suspected risk factors for breast cancer, to obtain information on sleep patterns and habits in the 10 years before the diagnosis and to ascertain lifetime occupational history including any job lasting 6 months or longer. For each job was defined the percentage of time worked during the day, the evening and on the graveyard shift (defined as 'beginning work after 19.00 and leaving work before 9.00'). Nine variables were characterized to define various aspects of a subject's exposure to light at night via sleep habits, bedroom lighting environment and shift work. Inter alia for the ten years prior to a diagnosis three variables further characterized the graveyard shift: i) ever worked during the graveyard shift, ii) hours per week worked during the graveyard shift, and iii) number of years worked at least one graveyard shift per week (one shift was considered $8 \mathrm{~h}$ ). The reported results stated that women who worked the graveyard shift at least once in the 10 years before diagnosis are at an approximately $60 \%$ increased risk (OR, 1.6; 95\% CI, 1.0-2.5) for breast cancer compared with 


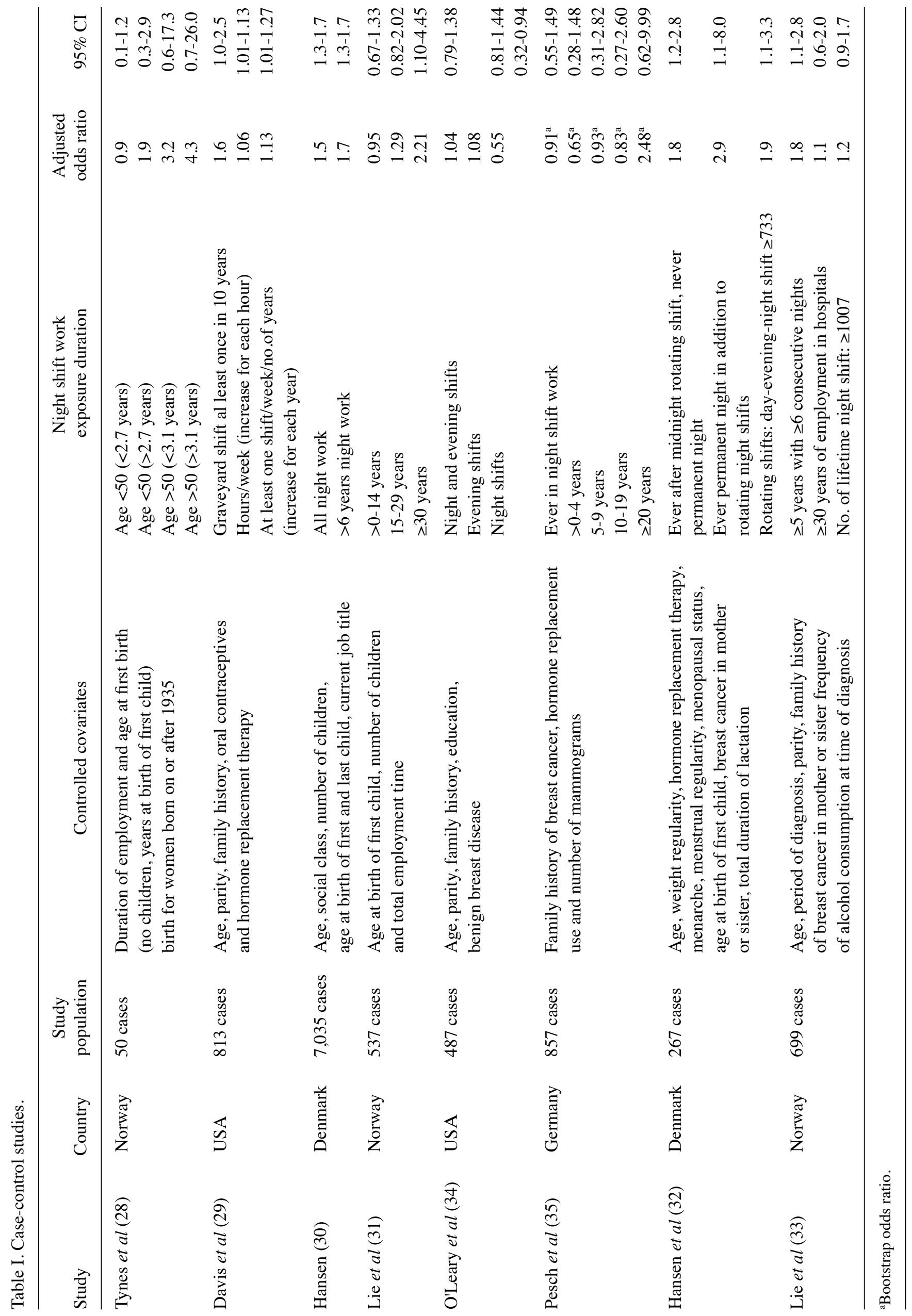




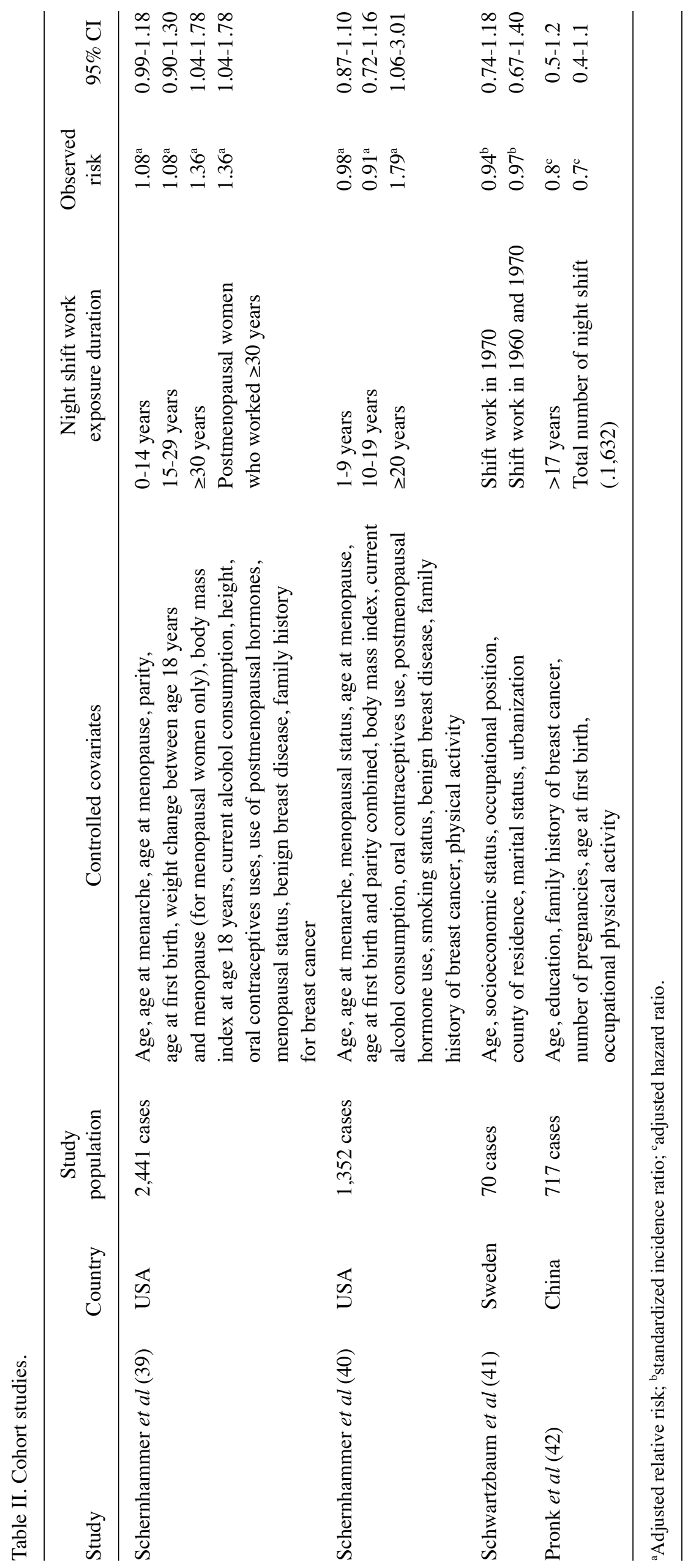


those who did not work the graveyard shift. The risk increased by number of hours per week on the graveyard shift (OR, 1.06 for each hour; 95\% CI, 1.01-1.13) and by the number of years working at least one graveyard shift per week (OR, 1.13 for each year; 95\% CI, 1.01-1.27). Considering hours per week as categorical variable it was found a trend of increase risk with more hours per week of graveyard shift work $(\mathrm{P}=0.03)$. These analyses were adjusted for some breast cancer risk factors as oral contraceptive use, hormone replacement therapy, parity and family history.

The study conducted by Hansen (30) comprised 7,565 cases of women with confirmed primary breast cancer, aged 30-54 years at the time of the diagnosis and identified in the Danish Cancer Registry. Information on past employment was reconstructed by record linkage with the files of the Danish nationwide pension found that retains computerized information about each job held from 1964. Of the breast cancer patients $7 \%$ (530 women) have no employment records (mainly housewives and assisting farmers' wives), leaving 7,035 female breast cancer patients who had an employment history. Individually matched controls on year of birth and gender were obtained from the file of the Central Population Registry. The employment histories of the control subjects were retrieved from the files of the pension found in the same way as for cases. A nationwide interview-based survey on living and working environment conditions showed that the highest prevalence of female workers with night time schedules (64-71\%) were employed in the manufacture of beverages, in land transport services, in catering and in airtransport services (36). The same 1978 survey showed that the average number of alcoholic drinks consumed was 3-6 times the median value for all female employees in the four high prevalence night shift work trades (36). Women were considered to work predominantly at night if they had been employed for at least half a year in one or more of the trades in which at least $60 \%$ of the female responders had night time schedules. Trades with 40-59\% female night time workers were excluded from the analyses. From the Danish Central Population Registry Hansen calculated the mother's age at the time her first and last child were born. The adjusted odds ratio for breast cancer among women employed for $>6$ months in trades with predominantly $(>60 \%)$ night work was in the range 1.1-1.9 in comparison with women employed in all other trades with $<40 \%$ night work. For all night work combined the OR was 1.5 (95\% CI, 1.3-1.7). Furthermore, it was affirmed that the relative risk tended to increase with increasing duration of night work, but only the results for women employed for $>6$ years in the specific trades were presented (OR, 1.7; 95\% CI, 1.3-1.7). Controlled covariates were number of children, age at birth of first child and age at birth of last child and current job title. Hansen described a 1.5-fold increase in risk for primary breast cancer among women who had worked for least half a year in any trade with predominantly night work. Furthermore, the relative risk tended to increase with increasing duration of night work.

In a Norwegian study, Lie et al (31) conducted a nested register-linked case-control study within a cohort of 44,853 women included in a national register of nurses. The registry, established in 1949, included all nurses who had graduated from a Norwegian nursing school between 1914 and 1980 and were alive in 1949 or born later. A total of 537 first occurrence breast cancer cases from 1960 to 1982 were identified by linkage to The Cancer Registry of Norway. For each case, four controls (alive and without breast cancer at the time the cases were diagnosed) were randomly drawn from the cohort and individually matched by year of birth for a total of 2,143 controls. The sources of exposure information were the Norwegian Board of Health's registry of nurses and census data from 1960, 1970 and 1980. First year of employment until termination of the last employment, date of diagnosis of the case, or the 67th birthday, whichever came first were the criteria to calculate the numbers of working years in the cohort. The first source was made by nurse's self-reported information and included job's beginning and end dates, work place, and to some extent, department or ward, but the last regular update was performed in 1968 and thereafter only sporadically. These data were integrated with the above mentioned census information by individual record linkage if the census' work code was 'nursing' or 'nursing and other care work' or the industry code was 'health work'. All work at infirmaries, was assumed to include night work, except for managerial jobs, teaching, and work at physiotherapy or outpatients' departments.

An odds ratio of 2.21 (95\% CI, 1.10-4.45; $\mathrm{P}=0.01$ ), adjusted for parity and total employment time as a nurse, was found among nurses who worked nights for 30 years or more compared with those who had not worked at night after graduation from nursing school. A 2-fold non-significant increase of risk (adjusted for total employment time as a nurse and parity) was found among 50 years and older nurses who worked nights for 30 or more years, but a statistically significant trend was observed $(\mathrm{P}=0.02)$. An elevated risk estimate after 15 or more years of night work, but no significant trend, was seen for nurses younger than 50 years. A similar pattern was found if the last 20 years of employment were disregarded. The conclusions reported in the study stated that for all ages combined, and for nurses aged 50 years or older, an increase of risk was observed in those who worked at night for 30 or more years, compared with those with no night work after graduation from nursing school. The increase was statistically significant for all ages, and borderline significant for women 50 years or older. For nurses younger than 50 years, a non-significant increase in risk was seen after 15 years of night work.

More recently, in 2011, a positive correlation between breast cancer risk and night shift work was highlighted by Hansen et al (32) and Lie et al (33). In contrast, a negative correlation was described by O'Leary et al (34) and Pesch et al (35) in the 2 remaining case-control studies.

The association between breast cancer and light-at-night exposures from both shift work and at home was evaluated by O'Leary et al (34). The study is based on data from the Electromagnetic Fields and Breast Cancer on Long Island Study (EBCLIS) part of the Long Island Breast Cancer Study Project (LIBCSP) (37). The study population included 467 breast cancer cases and 509 controls enrolled through an articulated procedure. The cases were diagnosed with first primary in situ or invasive breast cancer between 1996-1997. The exposure information were collected by interviews including location, start and end dates for each job held during the 15 -year period prior to the reference date (date of diagnosis for cases or identification for controls). The frequency, 
duration, and type of shift work were determined for each of these jobs. Evening shifts were defined as a shift started in the afternoon and ended as late as 2:00 a.m., while an overnight shift was described as a shift starting as early as 7:00 p.m. and continuing until the following morning. The referent group for these analyses included women who had never held jobs involving shift work. Statistical analyses demonstrated a negative association among any overnight shift work and breast cancer with an odds ratio, adjusted for age, parity, family history, education and previous benign breast disease, of 0.55 (95\% CI, 0.32-0.94). The aOR for overnight shift work but no evening shift work was 0.64 (95\% CI, 0.28-1.45). Findings were similar for pre- and postmenopausal women, for women $<65$ years of age, for invasive cases, and by estrogen receptor status. No association was found between breast cancer and increasing number of years working one or more overnight shift per week with an OR of 0.32 (95\% CI, 0.12-0.83) for the longest exposure category ( $\geq 8$ years). When considering overall shift work (evening or overnight shifts), they found no association with breast cancer risk. However, when they considered evening and overnight shift work separately, there was a negative association with overnight shift work, with no significant results for evening shift work.

Pesch et al (35) showed the risk estimates of night work for breast cancer in German women from the GENICA (Gene Environment Interaction and Breast Cancer) study. GENICA was a German population-based case-control study that enrolled 1143 incident breast cancer cases and 1,155 population controls between 2000 and 2004. Cases were enrolled from the major hospitals of the region and were women with histopathologically confirmed breast cancer diagnosed within six months before enrolment. Controls were ascertained as a random sample from the population registries of the study region and frequency matched to cases by age in 5-year classes. Night shift work was defined as fulltime period work between 24.00-05.00 hours according to the International Labor Organization (ILO) convention (www.ilo.org/ilolex/ cgi-lex/convde.pl?C171). Risk was assessed by: i) having ever done night work for $\geq 1$ year, ii) its duration, iii) the cumulative number of night shifts, iv) age at first incidence of night work, and v) time since last night work. The final statistical analysis was performed on 857 GENICA cases and 892 controls that derived from the original population through a more detailed interview concerning their use of hormone and shift work status. The group calculated risk estimates as odds ratios (OR) with $95 \%$ confidence intervals $(95 \% \mathrm{CI})$ adjusted for several potential confounders: menopausal status, education, breast cancer in mother or sister, parity, age at first birth, duration of oral contraceptive and hormone therapy use, BMI, smoking, number of mammograms until two years before interview, and lifetime breastfeeding in months. The results showed that, compared to women employed in day shifts only, both shift and night work were not associated with breast cancer risk (OR, 0.96; 95\% CI, 0.67-1.38 and OR, 0.91; 95\% CI, 0.55-1.49, respectively). Some positive associations were found during the analyses but they were not statistically significant. Furthermore, no significant trend for a cumulative number of night shifts $(\mathrm{P}=0.14)$, years in night shift $(\mathrm{P}=0.16)$, and time since last night shift $(\mathrm{P}=0.09)$ were found. In this study, having ever done night shift work was not associated with an increased breast cancer risk. Cases experienced on average about 800 night shifts in comparison to 300 among controls. Long-term night work was found to be associated with a modestly increased breast cancer risk although this was statistically not significant.

In the most recent study, Hansen et al (32) provided further evidence that night shift-work increases the risk of breast cancer as the odds ratio increased with duration and cumulative overnight shifts; furthermore, the largest impact on risk is associated with the most disruptive shifts. The analysis of risk was performed among Danish nurses through an interviewbased case-control study nested within a cohort of 91,140 women members of the Danish Nurses Association (38). The final cohort was restricted to the 58,091 members, free of breast cancer, who were born between 1933 and 1970 and alive in 2001, to better assess detailed information on shift-work and potential confounders. A total of 310 cases of histological confirmed primary breast cancer were recognized between 2001 and 2003. Telephone interviews were conducted to collect individual information on occupational and non-occupational exposure leading to a further reduction of the cohort to 267 patients and 1,035 controls. Work's characteristics were defined with an accurate approach through the collection of specific information for each job held at least 1 year and through a classification of the job according to the most frequent occurring rotating shift system in Danish nurses. To characterise the shift-work in each job two partly overlapped variables were used: type of shift (permanent day, rotating day-evening, daynight, day-evening-night, other rotating and permanent night), with calculated lifetime duration of each shift system weighted by hours worked per week; and number of shifts after midnight per month ('graveyard shifts', beginning after 19 and ending before 9), with calculated lifetime cumulative numbers of such shifts based on the duration and number per month. The odds ratios were adjusted for age, weight regularity, use of hormone replacement therapy, age at menarche, menstrual regularity, menopausal status, age at birth of first child, breast cancer in mother or sister, total duration of lactation. The authors found a significantly increased odds ratio for breast cancer when work after midnight was compared with permanent day work. Among nurses having ever had permanent night shifts in addition to rotation night shifts the aOR was 2.9 (95\% CI, 1.1-8.0) and for after midnight shifts without permanent night shifts it was 1.8 (95\% CI, 1.2-2.8). The highest odds ratio associated with rotating shift type (long-term day-night shift work) was 2.6 (95\% CI, 1.8-3.8). This study had an innovative point of view analysing the risk according to different shift systems, including permanent night shifts. The results provided further evidence that night shift-work may increase the risk for breast cancer, the odds ratio tended to increase with duration and cumulative overnight shifts the largest impact on risk is associated with the most disruptive shifts.

In agreement, Lie et al (33) in another study confirmed the positive association between breast cancer risk and night shift work throughout a nested case-control study within a cohort of 49,402 Norwegian nurses. The cohort, established in 2004, was represented by nurses graduated from a nursing school between 1914 and 1985, on the basis of the Norwegian Board of Health's registry of nurses. Cases were included if diagnosed with a primary breast cancer in the period 1990 
and 2007, aged 35-74 years at diagnosis and alive by February 2009; furthermore, cases were grouped into eight 5-year age strata. Controls were nurses in the cohort without breast cancer prior to 2007 and alive by 2009. They were frequency matched within 5-year age stratum for each diagnostic year and for each diagnostic year $50 \%$ more controls than cases were selected in each age stratum. Overall 699 primary breast cancer cases identified and alive and 895 controls were interviewed and included in the study. In the study, if nothing else was stated, the term 'night work' included working periods from rotating, as well as permanent, night schedules and included the work of permanent night workers. The odds ratios for risk of breast cancer were estimated in relation with different exposure metrics: i) duration of employment in hospitals or other institutions; ii) duration of work schedules including $>3$ night shifts per month; iii) duration of work in schedules including night work; iv) cumulative no. of lifetime night shifts; v) lifetime average no. of night shifts per month; vi) duration of work schedules including a minimum of 3-7 consecutive night shifts. The analyses were adjusted for potential confounders: age, period of diagnosis, parity, and family history of breast cancer in mother or sister and frequency of alcohol consumption at time of diagnosis. Non-significant increased risks were observed for exposure to $\geq 30$ years in hospitals or other institutions (aOR, 1.1; 95\% CI, 0.6-2.0), for exposure to $\geq 12$ years in schedules including night work (aOR, 1.3; 95\% CI, $0.9-1.8), \geq 1,007$ night shifts during the lifetime (aOR, 1.2; 95\% CI, 0.9-1.7), and lifetime average number of $\geq 4$ night shifts per month (aOR, 1.2; 95\% CI, 0.8-1.6). Non-significant increased risks of breast cancer were observed in nurses who worked $\geq 5$ years with $\geq 4$ (aOR, 1.4; 95\% CI, 0.9-1.9) and $\geq 5$ (aOR, 1.6; 95\% CI, 1.0-2.4) consecutive night shifts. Significantly increased risks were seen in nurses who worked $\geq 5$ years with $\geq 6$ consecutive night shifts (aOR, 1.8; 95\% CI, 1.1-2.8). In the new study, Lie et al suggests that breast cancer risk is related to number of consecutive nightshifts (33).

\section{Cohort studies analyzing the relationship between breast cancer risk and shift work exposure}

Four prospective epidemiological studies, describing the relation between shift work and breast cancer, are reported in Table II (39-42). Schernhammer et al performed two large prospective cohort studies to assess the risk of breast cancer among nurses following their rotating nightshift work $(39,40)$. In the first study the authors analyzed a population of 78,562 nurses derived from the United States Nurses' Health Study $(43,44)$ to assess the risk of breast cancer among night shift worker in 10 years from 1988 to 1998. Night shift work was defined as 'rotating night shifts with at least three nights per months in addition to days or evenings'. The exposure information was collected by periodical questionnaire. Outcome information were reported by nurses themselves and confirmed by medical records, furthermore, the National Death Index was used to identify deaths among the non-respondents. At the end of the observation period 2,441 cases of breast cancer were confirmed between 1988 and 1998. The analysis of the relationship between total years on rotating night shift and breast cancer showed an adjusted relative risk (aRR) of 1.36 (95\% CI, 1.04-1.78) for those women who had worked 30 or more years on rotating night shifts compared with never workers. Higher duration of working shift work was modestly associated with an increased breast cancer risk $(\mathrm{P}=0.02)$. In analyses stratified by menopausal status, the relation of the duration of highest night shift group and breast cancer was slightly different in premenopausal (aRR, 1.66; 95\% CI, 0.81-3.40) and postmenopausal (aRR, 1.36; 95\% CI, 1.04-1.78) women; in the latter group the test for trend was statistically significant $(\mathrm{P}=0.05)$. In the premenopausal women group also a modest association (RR, 1.23; 95\% CI, 0.97-1.55) was observed among those who had worked 1-14 years on rotating night shifts. The relative risk was adjusted for several potential confounders: age, age at menarche, age at menopause, parity, age at first birth, weight change between age 18 years and menopause (for menopausal women only), body mass index at age 18 years, current alcohol consumption, height, oral contraceptive use, use of postmenopausal hormones, menopausal status, benign breast disease and family history of breast cancer. In conclusions, in this prospective study the risk of breast cancer was statistically significantly elevated in postmenopausal women who worked for 30 or more years on rotating night shifts, compared with those who never worked rotating night shifts and among premenopausal women an increased breast cancer risk of 23\% after 1-14 years of shift work.

In the second study, Schernhammer et al (40) analyzed the relation between night shift work and breast cancer risk in a cohort of premenopausal nurses, highlighting that this was the first study analyzing the risk of breast cancer in this type of cohort. The Nurses' Health Study II began in 1989 and enrolled 115022 nurses aged 25-42 years as study population. The assessment of night shift work status was carried out through self-reported information on the questionnaires filled out in 1989, 1991, 1993 and 1997. In 2001, the participants were queried, retrospectively, for the time periods 1993-1995 and 1997-1999, due to a lack of night work information in the 1995 and 1999 questionnaires. Night shift work was defined as in the previous study of the group (39). Questions were asked regarding both the amount of month working in rotating night shift (six categories: 0, 1-4, 5-9, 10-14, 15-19 and 20 or more) and permanent night shifts for 6 or more months. A total of 1,352 breast cancer cases, occurred between 1989 and 2001, were identified by self-reports confirmed by medical records and the National Death Index. In the analyses women were classified by the lifetime total numbers of years they had worked rotating night shift until the date of diagnosis. Other analyses were equivalent with the procedures of the previous Nurses' Health Study including the potential confounders (39). The multivariate-adjusted RR was 1.79 (95\% CI, 1.06-3.01) for women who had worked for 20 or more years on rotating night shift compared with woman who had never worked this schedule with a P-value for trend of 0.65 . No results were presented for permanent night shift work. Overall, in this study the risk of breast cancer was found to be modestly elevated in women who worked for 20 or more years on rotating night shifts compared with those who never worked rotating night shifts.

In contrast, different results were reported by Schwartzbaum et al (41). The authors performed a register-based cohort study covering all members of the Swedish population who were gainfully employed (working at least $\geq 20 \mathrm{~h}$ per week) and who 
were included in both the 1960 and 1970 population censuses. These workers were followed from 1971 through 1989 or to the date of their death, whichever came first. Information about date of death was obtained from the Swedish Cause of Death Register. All of the cases of cancer that occurred within the study were identified from the nationwide Swedish Cancer Register. Based on data obtained by an annual survey conducted by Statistics Sweden during 1977-1981, the shift workers were defined 'as those who reported that their workplace had a rotating schedule with three or more possible shifts per day or had work hours during the night (any hour between 01:00 and 04:00) at least 1 day during the week preceding the interview'. Finally they 'calculated the percentage of shift workers in each combination of job title and industry in the survey'. The final definition of shift worker people used in the analyses was 'people working in job-title and industry combinations with at least $40 \%$ shift workers' but analyses were made also on those working in occupation-industry combinations in which at least $70 \%$ of the participants were shift workers. The cancer incidence among the exposed persons was compared with that of people in occupation-industry combinations in which less than $30 \%$ stated that they were shift workers. Overall $3 \%$ of the men $(69,759)$ and $0.3 \%$ of the women $(3,057)$ worked in occupations in which at least $40 \%$ was shift workers. Among them, 6,792 newly diagnosed cancer cases were identified in the national cancer register during the follow-up period. Standardized incidence ratios (SIR) were used to compare the adjusted cancer incidence rates for shift workers with those for non shift workers. The SIR for breast cancer was $0.94(95 \%$ CI, 0.74-1.18) and overall the number of breast cancer cases observed was close to the expected. Similar results were found when analyzing workers of jobs with $>70 \%$ shift workers. No evidences were found for an association between shift work and breast cancer incidence rates. Results were adjusted for potential confounding by age, socioeconomic status, occupational position (employed manager, other employee, self-employed with employees, self-employed without employees) and county of residence.

In agreement with the overall findings reported by Schwartzbaum (41), Pronk et al did not show any association between night shift work and breast cancer risk in a cohort study of Chinese women (42). This prospective populationbased cohort study of females was conducted among 73,049 women (recruited out of 81,170 between 1996 and 2000) without prevalent cancer at baseline and that had held at least one job outside the home. A biennial in-person interviews (2000-2002; 2002-2004; 2004-2007) and an annual record linkage to the Shanghai Cancer Registry and the Shanghai vital statistics database were the source of outcome information. A job exposure matrix classification of night-shift work, developed by a Chinese industrial hygienist, was used to calculate lifetime cumulative exposure. Night shift work was described 'as starting work after $10 \mathrm{pm}$ at least 3 times a month for over 1 year'. Data on the average number of night shifts worked per week, the duration of shift work (years), and the years of starting and ending shift work were also collected. Hazard ratios $(95 \%$ CI) obtained by statistical analyses were adjusted for age, education, family history of breast cancer, number of pregnancies, age at first birth, and occupational physical activity. During a 9-year follow-up period 717 women were newly diagnosed with an invasive malignant neoplasm of the breast. No statistical significance was reached by any risk estimated in the analyses and no consistent dose-response patterns were observed. Women in the highest categories of duration (adjusted Hazard Ratio, 0.8; 95\% CI, 0.5-1.2) and cumulative night shift work (adjusted Hazard Ratio, 0.7; 95\% CI, 0.4-1.1) and women who started night shift work after age 30 years (adjusted Hazard Ratio, 0.7; 95\% CI, 0.5-1.2) showed the greatest reductions in comparison with women who had never worked night shifts ( $\mathrm{P} \leq 0.05$ for all 3 associations).

\section{Discussion}

Breast cancer risk among night shift workers represents an important topic of study among researchers interested in occupational medicine, oncology and epidemiology. In 2007, the International Agency on Research on Cancer (IARC) classified 'shift work that involves circadian disruption' as 'probably carcinogenic to humans' (Group 2A) on the basis of 'limited evidence in humans for the carcinogenicity of shift work that involves night work', and 'sufficient evidence in experimental animals for the carcinogenicity of light during the daily dark period (biological night)' (45).

The two most recent studies, conducted by Hansen et al (32) and Lie et al (33), emphasize that night shift work represents a concrete risk of breast cancer because in both studies the main IARC indications have been developed. However, the Achilles heel of previous studies is represented by different reasons: i) the number of studies is still limited and not homogeneous, ii) the risk achieved, although significant, is too moderate; iii) the definition of night shift exposure is very rough, including the different duration of shift work exposure reported in the studies; iv) shift workers, during their working life, often change their shift schedules; v) the uncertain assessment of concurrent risk factors, confounders, or mediating factors (age at menarche, smoking and body mass index, menopause, number of children, age at birth of first child, parity, family history of breast cancer, oral contraceptive use, hormonal replacement therapy, benign breast diseases, and socioeconomic status, total duration of lactation).

To make order on this matter the IARC working group believes that several factors should be investigated for future epidemiological cancer studies: shift system (start time of shift, number of hours per day, rotating or permanent, speed and direction of a rotating system, regular or irregular); years on a particular non-day shift schedule and cumulative exposure to the shift system over the subject's working life; shift intensity (time off between successive work days on the shift schedule) (45). These factors are based in part on the biological considerations that workers on rotating or mixed night shift should have the highest cancer risk because they do not retrain to an altered circadian risk and adaptation speed can occur with different speed in relation to a phase delay or a phase advance shift (46-48).

The most valid hypotheses on the causal relation of shift work and breast cancer were connected to the alteration of the circadian system and to the idea that exposure to light-at-night during night shift work is related to a reduction of melatonin output (23). 
In the mammalian organism, the circadian system is organized in a hierarchical way so that a master oscillator in the suprachiasmatic nuclei (SCN) in the hypothalamus regulates the downstream peripheral oscillators via humoral, endocrine, and neural signals $(49,50)$ into a coherent time organization favouring optimal function $(47,51)$. Circadian rhythms in cell and organ physiology are driven and controlled by an autoregolatory transcription-translation feedback loop that regulates the expression of clock and clock-related genes, which are present in all metabolizing, nucleated cells of the body in a time-specific manner (52-54). Circadian clock genes control numerous cell cycle-related genes, cell cycle check points and tumor-suppressor genes and modulate transcription factors such as cyclin B1, Cdc2 kinase and cell division (55-57). Endocrine target tissues, such as breast cancer, appear to be especially prone to tumor development after circadian disruption from LAN, a process in which the suppression of melatonin may play an important role $(31,40)$. But also non-endocrine tumors in rodents were found to exhibit accelerated development after repeated phase shift suggesting circadian cell cycle related mechanism of carcinogenesis and or promotion $(58,59)$. It has been demonstrated that in vivo pharmacological inhibition of light-induced MAPK pathway activation blocked RSK-1 phopshorylation, indicating that RSK-1 activity is regulated by the MAPK pathway. The authors identified RSK-1 as a light- and clock-regulated kinase and raised the possibility that it contributes to entrainment and timing of the circadian pacemaker (60). Of note, MAPK pathway is involved in development of many cancers including breast cancer (61) also known as an endocrine-associated cancer $(62,63)$.

Melatonin may act on initiation, promotion and progression of tumors. A decrease of melatonin production favours an upregulation of the gonadal axis, as demonstrated among shift workers who had an increase in circulating estrogen after prolonged exposure to shift work (64). Prolonged exposure and or increased cellular response to estrogens during a woman's lifetime are a well-known risk factor for breast cancer $(65,66)$. Moreover, melatonin acts as a free radical scavenger directly or indirectly via activation of the glutathione antioxidative pathways (67-69). Melatonin acts as a response modifier to estrogens: i) exerts an antiestrogenic effect with interaction with $\operatorname{ER} \alpha(70,71)$; ii) counteracts the effect of estradiol on breast cancer cell proliferation, invasiveness and telomerase activity (72-76); iii) downregulates both the expression of protein growth factors and the proto-oncogenes stimulated by estrogens $(77,78)$; and iv) downregulates the epidermal growth factor receptor 2 (HER2/neu) (79).

Overall, the results of the present study suggest that there is still a need to reduce the incidence of cancer by analyzing the cancer risk factors; one of these might be the night shift work that is growing in the industrialized countries. On these bases, our research group has recently designed a casecontrol study with the aim to better understand if night shift work may be considered a true risk factor for breast cancer. Moreover, breast cancer biopsy specimens from patients with night shift work exposure will be analyzed to investigate if bio-molecular characteristics may be associated with night work exposure.

\section{References}

1. Parkin DM, Bray F, Ferlay J and Pisani P: Global cancer statistics, 2002. CA Cancer J Clin 55: 74-108, 2005.

2. Bray F, McCarron P and Parkin DM: The changing global patterns of female breast cancer incidence and mortality. Breast Cancer Res 6: 229-239, 2004.

3. Althuis MD, Dozier JM, Anderson WF, Devesa SS and Brinton LA: Global trends in breast cancer incidence and mortality 1973-1997. Int J Epidemiol 34: 405-412, 2005.

4. Parkin DM and Fernandez LM: Use of statistics to assess the global burden of breast cancer. Breast J 12: 70-80, 2006.

5. Madigan MP, Ziegler RG, Benichou J, Byrne C and Hoover RN: Proportion of breast cancer cases in the United States explained by well-established risk factors. J Natl Cancer Inst 87: 1681-1685, 1995.

6. Sacco AJ, Kaaks R and Little RE: Breast cancer: occurrence, risk factors and hormone metabolism. Expert Rev Anticancer Ther 3: 546-562, 2003.

7. Yager JD and Davidson NE: Estrogen carcinogenesis in breast cancer. N Engl J Med 354: 270-282, 2006.

8. Collaborative Group on Hormonal Factors in Breast Cancer: Breast cancer and hormonal contraceptives: collaborative reanalysis of individual data on 53297 women with breast cancer and 100239 women without breast cancer from 54 epidemiological studies. Lancet 347: 1713-1727, 1996.

9. Hamajima N, Hirose K, Tajima K, et al: Alcohol, tobacco and breast cancer - collaborative reanalysis of individual data from 53 epidemiological studies, including 58,515 women with breast cancer and 95,067 women without the disease. Br J Cancer 87: 1234-1245, 2002.

10. Krebs EE, Taylor BC, Cauley JA, Stone KL, Browman PJ and Ensrud KE: Measures of adiposity and risk of breast cancer in older postmenopausal women. J Am Geriatr Soc 54: 63-69, 2006.

11. Hsieh CC, Trichopoulos D, Katsouyanni K and Yuasa S: Age at menarche, age at menopause, height and obesity as risk factors for breast cancer: associations and interactions in an international case-control study. Int J Cancer 46: 796-800, 1990.

12. Straif K, Baan R, Grosse Y, Secretan B, Ghissassi FEL, Bouvard V, Altieri A, Benbrahim-Tallaa L and Cogliano V: Carcinogenicity of shift-work, painting, and fire-fighting. Lancet Oncol 8: 1065-1066, 2007.

13. Nagano M, Adachi A, Nakahama K, Nakamura T, Tamada M, Meyer-Bernstein E, Sehgal A and Shigeyoshi Y: An abrupt shift in the day/night cycle causes desynchrony in the mammalian circadian center. J Neurosci 23: 6141-6151, 2003.

14. Romon M, Nuttens MC, Fievet C, et al: Increased triglyceride levels in shift workers. Am J Med 93: 259-262, 1992.

15. Karlsson B, Knutson A and Lindhal B: Is there an association between shift work and having a metabolic syndrome? Results from a population based study of 27,485 people. Occup Environ Med 58: 747-752, 2001.

16. Morgan L, Hampton S, Gibbs M and Arendt J: Circadian aspects of postprandial metabolism. Chronobiol Int 20: 795-808, 2003.

17. Al-Naimi S, Hampton SM, Richard P, Tzung C and Morgan LM: Postprandial metabolic profiles following meals and snacks eaten during simulated night and day shift work. Chronobiol Int 21: 937-947, 2004.

18. Van Cauter E, Polonsky KS and Scheen AJ: Roles of circadian rhythmicity and sleep in human glucose regulation. Endocr Rev 18: 716-738, 1997.

19. Van Cauter E, Plat L and Copinschi G. Interrelations between sleep and somatotropic axis. Sleep 21: 553-566, 1998.

20. Hennig J, Kieferdorf P, Moritz C, Huwe S and Netter P: Changes in cortisol secretion during shift work: implications for tolerance to shift work. Ergonomics 41: 610-621, 1998.

21. Lac G and Chamoux A: Biological and psychological responses to two rapid shiftwork schedules. Ergonomics 47: 1339-1349, 2004.

22. Stevens RG: Electric power use and breast cancer: a hypothesis. Am J Epidemiol 125: 556-561, 1987.

23. Stevens RG: Artificial lighting in the industrialized world: circadian disruption and breast cancer. Cancer Causes Control 17: 501-507, 2006.

24. Megdal SP, Kroenke CH, Laden F, Pukkala E and Schernhammer ES: Night work and breast cancer risk: a systematic review and meta-analysis. Eur J Cancer 41: 2023-2032, 2005. 
25. Kolstad HA: Nightshift work and risk of breast cancer and other cancers: a critical review of the epidemiologic evidence. Scand J Work Environ Health 34: 5-22, 2008.

26. Hansen J: Risk of breast cancer after night and shift work: current evidence and ongoing studies in Denmark. Cancer Causes Control 17: 531-537, 2006.

27. Schernhammer E and Schulmeister K: Light at night and cancer risk. Photochem Photobiol 79: 318-318, 2004

28. Tynes T, Hannevik M, Andersen A, Vistnes AI and Haldorsen T: Incidence of breast cancer in Norwegian female radio and telegraph operators. Cancer Causes Control 7: 197-204, 1996.

29. Davis S, Mirick DK and Stevens RG: Night shift work, light at night, and risk of breast cancer. J Natl Cancer Inst 93: 1557-1562, 2001.

30. Hansen J: Increased breast cancer risk among women who work predominantly at night. Epidemiology 12: 74-77, 2001.

31. Lie JA, Roessink J and Kjaerheim K: Breast cancer and night work among Norwegian nurses. Cancer Causes Control 17: $39-44,2006$

32. Hansen J and Stevens RG: Case-control study of shift-work and breast cancer risk in Danish nurses: impact of shift systems. Eur J Cancer: Aug 16, 2011 (Epub ahead of print).

33. Lie JA, Kjuus H, Zienolddiny S, Haugen A, Stevens RG and Kjærheim K: Night work and breast cancer risk among Norwegian nurses: assessment by different exposure metrics. Am J Epidemiol 173: 1272-1279, 2011.

34. O'Leary ES, Schoenfeld ER, Stevens RG, Kabat GC, Henderson K, Grimson R, Gammon MD and Leske MC: Shift work, light at night, and breast cancer on Long Island, New York. Am J Epidemiol 164: 358-366, 2006.

35. Pesch B, Harth V, Rabstein S, Baisch C, Schiffermann M, Pallapies D, Bonberg N, Heinze E, Spickenheuer A, Justenhoven C, et al: Night work and breast cancer: results from the German GENICA study. Scand J Work Environ Health 36 : $134-141,2010$

36. Hansen EJ: The distribution of living conditions. Main results from the welfare survey. Part I. Theory, method, and summary. Copenhagen, Teknisk Forlag, 1978.

37. Gammon MD, Neugut AI, Santella RM, Teitelbaum SL, Britton JA, Terry MB, Eng SM, Wolff MS, Stellman SD, Kabat GC, et al: The Long Island Breast Cancer Study Project: description of a multi-institutional collaboration to identify environmental risk factors for breast cancer. Breast Cancer Res Treat 74: 235-254, 2002

38. Kjaer TK and Hansen J: Cancer incidence among a large cohort of female Danish registered nurses. Scand J Work Environ Health 35: 446-453, 2009.

39. Schernhammer ES, Laden F, Speizer FE, Willett WC, Hunter DJ, Kawachi I and Colditz GA: Rotating night shifts and risk of breast cancer in women participating in the nurses' health study. J Natl Cancer Inst 93: 1563-1568, 2001.

40. Schernhammer ES, Kroenke $\mathrm{CH}$, Laden $\mathrm{F}$ and Hankinson SE: Night work and risk of breast cancer. Epidemiology 17: 108-111, 2006.

41. Schwartzbaum J, Ahlbom A and Feychting M: Cohort study of cancer risk among male and female shift workers. Scand J Work Environ Health 33: 336-343, 2007.

42. Pronk A, Ji BT, Shu XO, Xue S, Yang G, Li HL, Rothman N, Gao YT, Zheng W and Chow WH: Night-shift work and breas cancer risk in a cohort of Chinese women Am J Epidemiol 171: 953-959, 2010

43. Stampfer MJ, Willett WC, Colditz GA, Rosner B, Speizer FE and Hennekens $\mathrm{CH}$ : A prospective study of postmenopausal estrogen therapy and coronary heart disease. N Engl J Med 313: 1044-1049, 1985

44. Willett WC, Stampfer MJ, Colditz GA, Rosner BA, Hennekens CH and Speizer FE: Dietary fat and the risk of breast cancer. N Engl J Med 316: 22-28, 1987.

45. Stevens RG, Hansen J, Costa G, Haus E, Kauppinen T, Aronson KJ, Castaño-Vinyals G, Davis S, Frings-Dresen MH, Fritschi L, et al: Considerations of circadian impact for defining 'shift work' in cancer studies: IARC Working Group Report. Occup Environ Med 68: 154-162, 2011.

46. Klein K, Wegmann H, Athanassenas G, Hohlweck H and Kuklinski P: Air operations and circadian performance rhythms. Aviat Space Environ Med 47: 221-230, 1976.

47. Yamazaki S, Numano R, Abe M, Hida A, Takahashi R, Ueda M, Block GD, Sakaki Y, Menaker M and Tei H: Resetting central and peripheral circadian oscillators in transgenic rats. Science 288: $682-685,2000$
48. Haus E and Smolensky M: Biological clocks and shift work: circadian dysregulation and potential long-term effects. Cancer Causes Control 17: 489-500, 2006.

49. Schibler U: Circadian time keeping: the daily ups and downs of genes, cells, and organisms. Prog Brain Res 153: 271-282, 2006.

50. Balsalobre A, Marcacci L and Schibler U: Multiple signaling pathways elicit circadian gene expression in cultured Rat-1 fibroblasts. Curr Biol 10: 1291-1294, 2000.

51. Yoo SH, Yamazaki S, Lowrey PL, Shimomura K, Ko CH, Buhr ED, Siepka SM, Hong HK, Oh WJ, Yoo OJ, et al: PERIOD2::LUCIFERASE real-time reporting of circadian dynamics reveals persistent circadian oscillations in mouse peripheral tissues. Poc Natl Acad Sci USA 101: 5339-5346, 2004.

52. Miller BH, McDearmon EL, Panda S, Hayes KR, Zhang J, Andrews JL, Antoch MP, Walker JR, Esser KA, Hogenesch JB and Takahashi JS: Circadian and CLOCK-controlled regulation of the mouse transcriptome and cell proliferation. Proc Natl Acad Sci USA 104: 3342-3347, 2007.

53. Reppert SM and Weaver DR: Coordination of circadian timing in mammals. Nature 418: 935-941, 2002.

54. Lowre PL and Takahashi JS: Mammalian circadian biology: elucidating genome-wide levels of temporal organization. Ann Rev Genomics Hum Genet 5: 407-441, 2004.

55. Panda S, Antoch MP, Miller BH, Su AI, Schook AB, Straume M, Schultz PG, Kay SA, Takahashi JS and Hogenesch JB: Coordinated transcription of key pathways in the mouse by the circadian clock. Cell 109: 307-320, 2002.

56. Matsuo T, Yamaguchi S, Mitsui S, Emi A, Shimoda F and Okamura H: Control mechanism of the circadian clock for timing of cell division in vivo. Science 32: 255-259, 2003.

57. Fu L and Lee CC: The circadian clock: pacemaker and tumour suppressor. Nat Rev Cancer 3: 350-361, 2003.

58. Filipski E, Delaunay F, King VM, Wu MW, Claustrat B, GrechezCassiau A, Guettier C, Hastings MH and Francis L: Effects of chronic jet lag on tumor progression in mice. Cancer Res 64: 7879-7885, 2004.

59. Filipski E, King VM, Li X, Granda TG, Mormont MC, LiuX, Claustrat B, Hastings MH and Lévi F: Host circadian clock as a control point in tumor progression. J Natl Cancer Inst 94: 690-697, 2002.

60. Butcher GQ, Lee B, Hsieh F and Obrietan K: Light- and clockdependent regulation of ribosomal S6 kinase activity in the suprachiasmatic nucleus. Eur J Neurosci 19: 907-915, 2004

61. Ligresti G, Libra M, Militello L, Clementi S, Donia M, Imbesi R, Malaponte G, Cappellani A, McCubrey JA and Stivala F: Breast cancer: molecular basis and therapeutic strategies (Review). Mol Med Rep 1: 451-458, 2008

62. Truchet I, Jozan S, Baron S, Frongia C, Balaguer P, Richard-Foy H and Valette A: Estrogen and antiestrogen-dependent regulation of breast cancer cell proliferation in multicellular spheroids: Influence of cell microenvironment. Int J Oncol 32: 1033-1039, 2008.

63. Echiburù-Chau C, Roy D and Calaf GM: Deleterious MnSOD signals lead to abnormal breast cell proliferation by radiation and estrogen exposure. Int J Oncol 38: 1703-1711, 2011.

64. Schernhammer ES, Rosner B, Willett WC, Laden F, Colditz GA and Hankinson SE: Epidemiology of urinary melatonin in women and its relation to other hormones and night work. Cancer Epidemiol Biomarkers Prev 13: 936-943, 2004.

65. Gail MH, Brinton LA, Byar DP, Corle DK, Green SB, Schairer C and Mulvihill JJ: Projecting individualized probabilities of developing breast cancer for white females who are being examined annually. J Natl Cancer Inst 81: 1879-1886, 1989.

66. Nelson HD, Humphrey LL, Nygren P, Teutsch SM and Allan JD: Postmenopausal hormone replacement therapy: scientific review. JAMA 288: 872-881, 2002

67. Blask DE, Sauer LA and Dauchy RT: Melatonin as a chronobiotic/anticancer agent: cellular, biochemical, and molecular mechanisms of action and their implications for circadian-based cancer therapy. Curr Top Med Chem 2: 113-132, 2002.

68. Blask DE, Dauchy RT, and Sauer LA: Putting cancer to sleep at night: the neuroendocrine/circadian melatonin signal. Endocrine 27: 179-188, 2005

69. Reiter RJ: Mechanisms of cancer inhibition by melatonin. J Pineal Res 37: 213-214, 2004.

70. Baldwin WS and Barrett JC: Melatonin: receptor-mediated events that may affect breast and other steroid hormone-dependent cancers. Mol Carcinog 21: 149-155, 1998. 
71. Collins A, Yuan L, Kiefer TL, Cheng Q, Lai L and Hill SM: Overexpression of the MT1 melatonin receptor in MCF-7 human breast cancer cells inhibits mammary tumor formation in nude mice. Cancer Lett 189: 49-57, 2003.

72. Blask DE and Hill SM: Effects of melatonin on cancer: studies on MCF-7 human breast cancer cells in culture. J Neural Transm Suppl 21: 433-449, 1986.

73. Cos S, Fernández R, Güézmes A and Sánchez-Barceló EJ: Influence of melatonin on invasive and metastatic properties of MCF-7 human breast cancer cells. Cancer Res 58: 4383-4390, 1998.

74. Leon-Blanco MM, Guerrero JM, Reiter RJ, Calvo JR and Pozo D: Melatonin inhibits telomerase activity in the MCF-7 tumor cell line both in vivo and in vitro. J Pineal Res 35: 204-211, 2003.

75. Martínez-Campa C, Alonso-González C, Mediavilla MD, Cos S, González A, Ramos S and Sanchez-Barcelò EJ: Melatonin inhibits both ER alpha activation and breast cancer cell proliferation induced by a metalloestrogen, cadmium. J Pineal Res 40: 291-296, 2006.
76. Martínez-Campa C, Alonso-González C, Mediavilla MD, Cos S, González A, Ramos S and Sánchez-Barceló EJ: Melatonin down regulates hTERT expression induced by either natural estrogens (17b-estradiol) or metalloestrogens (cadmium) in MCF-7 human breast cancer cells. Cancer Lett 268: 272-277, 2008.

77. Molis TM, Spriggs LL, Jupiter Y and Hill SM: Melatonin modulation of estrogen-regulated proteins, growth factors, and proto-oncogenes in human breast cancer. J Pineal Res 18: 93-103, 1995.

78. Mediavilla MD, Güezmez A, Ramos S, Kothari L, Garijo F and Sánchez Barceló EJ: Effects of melatonin on mammary gland lesions in transgenic mice overexpressing N-ras protooncogene. J Pineal Res 22: 86-94, 1997.

79. Baturin DA, Alimova IN, Anisimov VN, Popovich IG, Zabezhinski MA, Provinciali M, Mancini R and Franceschi C: The effect of light regimen and melatonin on the development of spontaneous mammary tumors in HER-2/neu transgenic mice is related to a downregulation of HER-2/neu gene expression. Neuro Endocrinol Lett 22: 441-447, 2001. 